Int. J. Morphol.,

29(1):90-93, 2011.

\title{
A Complex Variation of the Parietal and Visceral Branches of the Abdominal Aorta
}

\author{
Una Compleja Variación de las Ramas Parietales y Viscerales de la Parte Abdominal de la Aorta
}

\author{
"Nadire Unver Dogan; "Zeliha Fazliogullari; "**Mehmet Tugrul Yilmaz; \\ "Ismihan Ilknur Uysal; **Aynur Emine Cicekcibasi; *Mahinur Ulusoy \& ** Pervin Gunaslan
}

UNVER DOGAN, N.; FAZLIOGULLARI, Z.; YILMAZ, M. T.; UYSAL, I. I.; CICEKCIBASI, A. E.; ULUSOY, M. \& GUNASLAN, P. A. Complex variation of the parietal and visceral branches of the abdominal aorta. Int. J. Morphol., 29(1):90-93, 2011.

SUMMARY: Variations in the branches of the abdominal aorta were determined during a routine abdominal region dissection of a 70-year-old male cadaver. Left gastric artery arose as the first root from antero-lateral of aorta. Coeliacomesenteric trunk occurred as a thick root. After $29.9 \mathrm{~mm}$, coeliacomesenteric trunk bifurcated as coeliac trunk and superior mesenteric artery. Coeliac trunk bifurcated as splenic artery and common hepatic artery. These multiple variations which change the normal anatomic structure of the abdominal aorta have to be kept in mind by surgeons, radiologists and anatomists.

KEY WORDS: Abdominal aorta; Coeliacomesenteric trunk; Anatomical variation.

INTRODUCTION

Aorta, the main artery of circulation, is divided into three according to its course; ascending aorta, arch of aorta and descending aorta. Passing through aortic hiatus underside the face of Th 12, aorta lies as abdominal aorta which is 13 $\mathrm{cm}$ long and ends underside of $\mathrm{L} 4$. The branches of the abdominal aorta can be classified as single-double or visceral-parietal. Double visceral branches are (middle suprarenal artery, renal artery, testicular artery (ovarian artery), single visceral branches are (coeliac trunk, superior mesenteric artery, inferior mesenteric artery), double parietal branches are (inferior phrenic artery, lumbar arteries), and single parietal branch is median sacral artery (Standring, 2005).

Knowledge of such case has important clinical significance in an abdominal operation or invasive arterial procedure, that is by procedure and liver transplantation, laparoscopic surgery, and radiological procedures in the upper abdomen.

\section{CASE REPORT}

Variations in the branches of the abdominal aorta were determined during a routine abdominal region dissection of a 70-year-old male cadaver at the Anatomy Department of Meram Medical Faculty, Selcuk University. Left gastric artery arose as the first branch $(2.71 \mathrm{~mm}$ thick) from anterolateral side of the aorta $49.01 \mathrm{~mm}$ under the diaphragm and after $14.07 \mathrm{~mm}$, the left inferior phrenic artery originates $(2.03 \mathrm{~mm}$ thick) (Figs. 1,2). The coeliacomesenteric trunk originates as a thick branch (16.89mm thick) $57.88 \mathrm{~mm}$ after diaphragm. The coeliacomesenteric trunk originates $8.87 \mathrm{~mm}$ distal from the left gastric artery. After $29.9 \mathrm{~mm}$, the coeliacomesenteric trunk bifurcated as coeliac trunk $(7.11 \mathrm{~mm}$ thick) and superior mesenteric artery $(8.88 \mathrm{~mm}$ thick). The coeliac trunk, after $9.27 \mathrm{~mm}$, bifurcated as splenic artery $(5.56 \mathrm{~mm}$ thick) and common hepatic artery $(5.54 \mathrm{~mm}$ thick) (Figs. 1,2). The right renal artery $(8.61 \mathrm{~mm}$ thick) originates from the anterolateral surface of the abdominal aorta $7.17 \mathrm{~mm}$ after coeliacomesenteric trunk. Right renal artery originated two branches : right inferior phrenic artery

\footnotetext{
* Department of Anatomy, Selcuklu Medical Faculty, Selcuk University, Konya, Turkey.

** Department of Anatomy, Meram Medical Faculty, Selcuk University, Konya, Turkey.

This study was presented as an poster presentation in Anatomist 2009, $10^{\text {th }}$ Congress of European Association of Clinical Anatomy. 2-5 September, Turkey. 
$(3.11 \mathrm{~mm}$ thick) and superior segmental artery $(3.82 \mathrm{~mm}$ thick) after $14.14 \mathrm{~mm}$ (Figs. 1,3). The right inferior phrenic artery bifurcated after $50.23 \mathrm{~mm}$ and both branches distributed inferior of the diaphragm (Fig. 3).

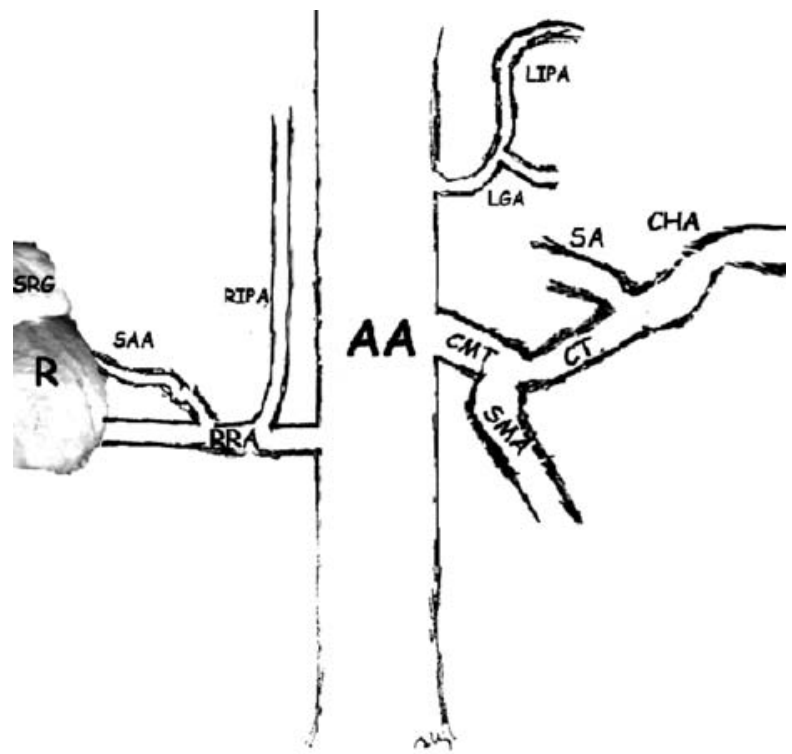

Fig. 1. Diagramming the variations of arteries rooted from abdominal aorta. LIPA; left inferior phrenic artery; LGA, left gastric artery; CMT, coeliacomesenteric trunk CT, coeliac trunk; CHA, common hepatic artery; SA, splenic artery; SMA, superior mesenteric artery; RRA, right renal artery; RIPA, right inferior phrenic artery SAA, superior segmental artery; R, kidney; SRG, suprarenal gland; AA, abdominal aorta.

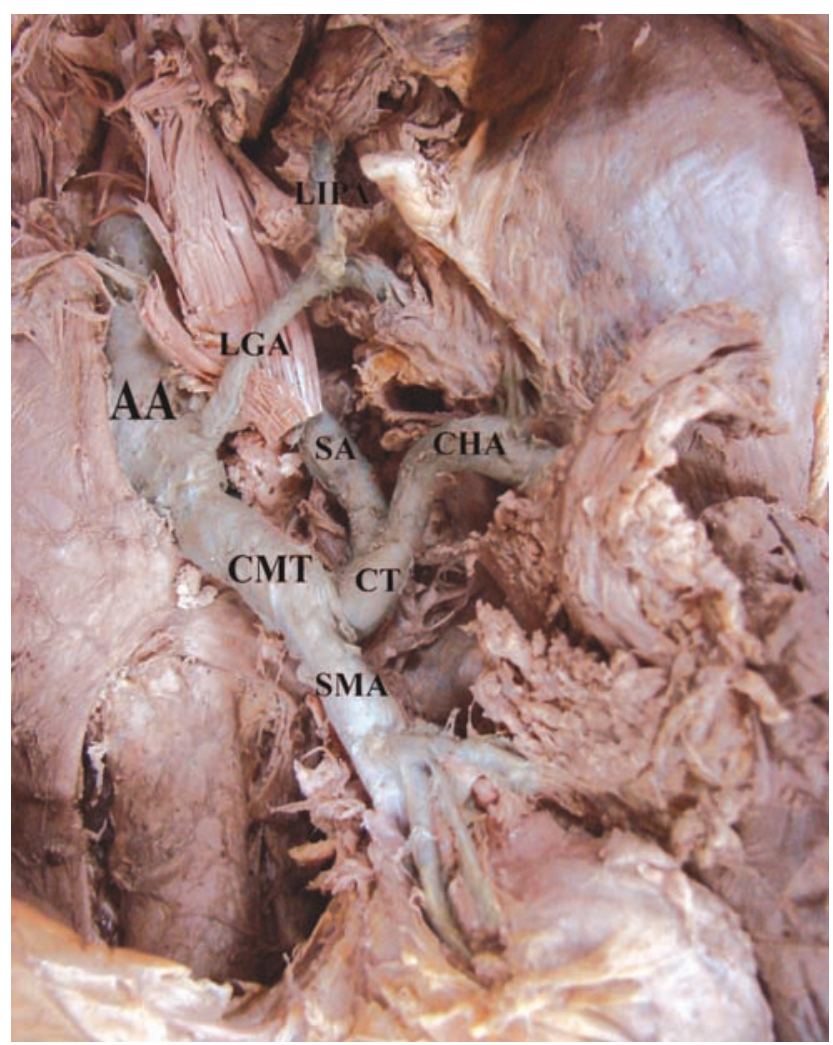

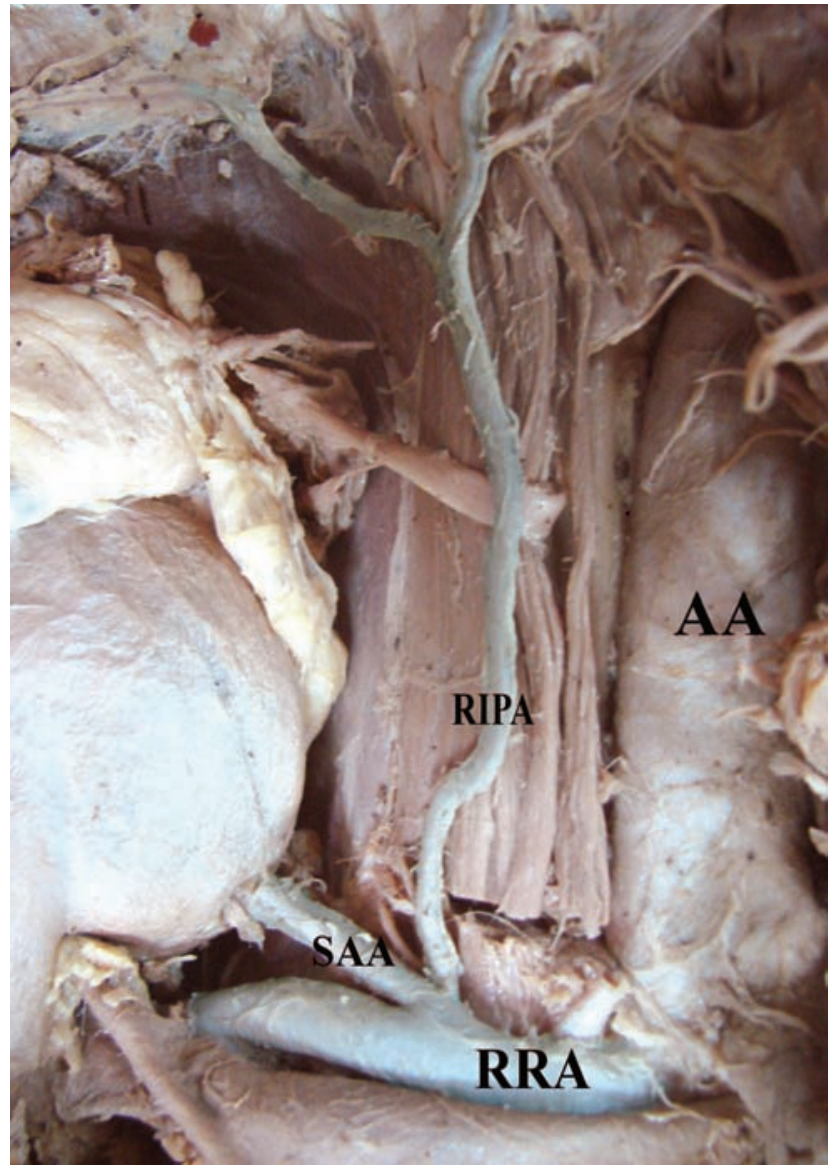

Fig. 3. Right renal artery (RRA); right inferior phrenic artery (RIPA) and superior segmental artery (SAA) parted from the abdominal aorta (AA).

\section{DISCUSSION}

The coeliac trunk, a wide ventral branch just below the aortic hiatus, passes almost horizontally forwards and slightly right above the pancreas and the splenic vein, dividing into the left gastric artery, common hepatic artery and splenic artery (Standring). Van Damme \& Bonte (1985) reported in an angiographic study the trifucation of coeliac trunk occurred in the $86 \%$ of the cases; bifurcation of coeliac trunk (common hepatic and splenic arteries) was $12 \%$. In our case, the coeliac trunk bifurcated as common hepatic artery and splenic artery.

Left gastric artery, the smallest coeliac branch, ascends to the left, posterior to the omental bursa, to the cardiac end of the stomach. It is near the inferior phrenic artery and medial

Fig. 2. Dissection the variations of arteries rooted from abdominale aorta. LIPA, left inferior phrenic artery; LGA, left gastricartery; CMT, coeliacomesenteric trunk CT, coeliac trunk; CHA, common hepatic artery; SA, splenic artery; SMA, superior mesenteric artery; AA, abdominal aorta. 
or anterior the suprarenal gland (Standring). The left gastric artery arose in about $90 \%$ of all cases from the coeliac trunk (Ylldırım et al., 1998; Hitawashi \& Yoshida, 2003). In dissection studies of cadavers where the left gastric artery arose separately from the aorta, different rates were reported 1.9-15 (Lipshutz, 1917; Van Damme \& Bonte; Yıldırım et al.). Saga et al. (2005) reported a case with left gastric artery (outer diameter $3 \mathrm{~mm}$ ) originated from the right margin of the mid-half of the abdominal aorta and Yamaki et al. (1995) reported cases with left gastric artery (outer diameter $4 \mathrm{~mm}$ ) originating from the anterior surface of the abdominal aorta. In our case, it was observed that left gastric artery originated from the left lateral side of the abdominal aorta and its outer diameter was $2.71 \mathrm{~mm}$.

The inferior phrenic arteries usually arise from the abdominal aorta, just above the level of the coeliac trunk. Occasionally the arteries originate from a common aortic origin with the coeliac trunk, from the coeliac trunk itself or from the renal artery. They contribute to the arterial supply of the diaphragm (Standring). There are cadaver studies (2-2.9\%) (Piao et al., 1998; Loukas et al., 2005) and radiological studies (0.65-3.7\%) (Gwon et al., 2007; Ozbulbul et al., 2009) reporting that left inferior phrenic artery is a branch of the left gastric artery. In this study we observed that left inferior phrenic artery is a branch of the left gastric artery.

The right inferior phrenic artery originates of the renal artery which has been reported in cadaver studies (4.3-17\%) (Piao et al.; Loukas et al.) and radiological studies (7.7-15\%) (Hitawashi et al.; Gwon et al.; Ozbulbul et al.). We established that right renal artery gives origin to the right inferior phrenic artery at $14.14 \mathrm{~mm}$ after it left abdominal aorta and this artery supplies the diaphragm after $50.23 \mathrm{~mm}$ in our case.

The vitelline arteries, initially a number of paired vessels supplying the yolk sac, gradually fuse and form the arteries located in the dorsal mesentery of the gut. In adult, the arteries are represented by the coeliac trunk, superior and inferior mesenteric arteries. These vessels supply the derivatives of the foregut, midgut, and hindgut, respectively (Kahraman et al., 2001; Saeed et al., 2003; Cicekcibasi et al., 2005a). In rare cases, the coeliac trunk and the superior mesenteric artery may be fused to a coeliacomesenteric trunk (Cavdar et al., 1997; Detroux et al., 1998; Agarwal et al., 2000; Cicekcibasi et al., 2005b; Yi et al., 2007). A common origin of coeliac trunk and superior mesenteric artery from the abdominal aorta is extremely rare. It has been reported in $0.5 \%$ of the population on the basis of 200 visceral arteriograms and $\% 0.25$ on the basis of 500 anatomic dissections (Ruzicka \& Rossi, 1968; Mitchels et al., 1995). We observed a coeliacomesenteric trunk distant from $(57.88 \mathrm{~mm})$ the diaphragm. This common branch bifurcated into coeliac trunk and superior mesenteric artery at $29.90 \mathrm{~mm}$. In this case, the celiac trunk bifurcated in the common hepatic artery and the splenic artery.

Ciçekcibas, i et al. (2005b) reported in an adult cadaver a coeliacomesenteric trunk which originated: the left gastric artery, the common hepatic artery, the splenic artery, the left gastro-omental artery, the right and the left inferior phrenic arteries. Cavdar et al. reported a case which coeliacomesenteric trunk and both left and right arteries arose at almost the same level from the abdominal aorta. In this case, the coeliac trunk was bifurcated as splenic artery and common hepatic artery. The coeliacomesenteric trunk and renal arteries originated from different levels of the aorta.

The renal arteries are two of the largest branches of the abdominal aorta and originate laterally from the vessel just below the origin of the superior mesenteric artery. The right renal artery is longer and usually originates slightly higher than the left (Standring). However, some studies reported that both arteries originated at the same level from the aorta (Kosin'ski, 1994; Beregi et al., 1999; Ciçekcibas, i et al., 2005b). Renal arteries originated at he same level in our study. It was observed that the right inferior phrenic artery and superior segmental artery are branches of the right renal artery.

The number and the form of these multiple variations of abdominal aorta in a single cadaver have not been reported previously. These multiple variations which change the normal anatomic structure of the abdominal aorta should be considered by surgeons, radiologists and anatomists.

UNVER DOGAN, N.; FAZLIOGULLARI, Z.; YILMAZ, M. T.; UYSAL, I. I.; CICEKCIBASI, A. E.; ULUSOY, M. \& GUNASLAN, P. A. Una compleja variación de los ramas parietales y viscerales de la parte abdominal de la aorta. Int. J. Morphol., 29(1):90-93, 2011.

RESUMEN: Fueron encontradas, en un cadáver de sexo masculino de 70 años de edad durante una disección de rutina de la cavidad abdominal, variaciones de las ramas en la parte abdominal de la aorta. La arteria gástrica izquierda se originaba como la la primera rama antero-lateral de la aorta. El tronco celiacomesénterico se originó desde la aorta como una raíz gruesa. Después de 29,9mm, el tronco celiacomesentérico se dividió en el tronco celíaco y la arteria mesentérica superior. El tronco celíaco se dividió en las arterias esplénica y hepática común. Estas variaciones múltiples que cambian la estructura anatómica normal de la parte abdominal de la aorta tienen que ser tomada en consideración por los cirujanos, radiólogos y anatomistas.

PALABRAS CLAVE: Parte abdominal de la aorta; Tronco celiacomesentérico; Variación anatómica. 


\section{REFERENCES}

Agarwal, A.K.; Youssef, M.K.; Doyle, G.J. \& Wood, C.P. Coeliomesenteric trunk stenosis-a rare variation causing mesenteric ischaemia. Eur. J. Vasc. Endovasc Surg., 20:405-6, 2000.

Beregi, J. P.; Mauroy, B.; Willoteaux, S.; Mounier-Vehier, C.; Rémy-Jardin, M. \& Francke, J. P. Anatomic variation in the origin of the main renal arteries: spiral CTA evaluation. Eur. Radiol., 9:1330-4, 1999.

Cavdar, S.; Sehirli, U. \& Pekin, B. Celiacomesenteric trunk. Clin. Anat., 10:231-4, 1997.

Cicekcibasi, A. E.; Ziylan, T.; Salbacak, A.; Seker, M.; Büyükmumcu, M. \& Tuncer I. An investigation of the origin, location and variations of the renal arteries in human fetuses and their cilinical revelance. Ann. Anat., 4:421-7, 2005a.

Cicekcibasi, A. E; Uysal, I. I.; Seker, M.; Tuncer, I.; Büyükmumcu, M. \& Salbacak, A. A rare variation of the coeliac trunk. Ann. Anat., 4:387-91, 2005b.

Detroux, M.; Anidjar, S. \& Nottin, R. Aneurysm of a common celiacomesenteric trunk. Ann. Vasc. Surg., 12:78-82, 1998.

Gwon, D. I.; Ko, G. Y.; Yoon, H. K; Sung, K. B.; Lee, J. M.; Ryu, S. J.; Seo, M. H.; Shim, J. C.; Lee, G. J. \& Kim, H. K. Inferior phrenic artery: anatomy, variations, pathologic conditions, and interventional management. Radiographic, 3:687-705, 2007.

Hiwatashi, A. \& Yoshida, K. The origin of right inferior phrenic artery on multidedector row helicol CT. Clin. Imaging, 27:298-303, 2003.

Kahraman, G.; Marur, T.; Tanyeli, E. \& Yıldırım, M. Hepatomesenteric trunk. Surg. Radiol. Anat., 23:433-5, 2001.

Kosin'ski, H. Variability of places of origin of the human renal arteries. Folia Morphol., 53:111-6, 1994.

Lipshutz, B. A composite study of the coeliac axis artery. Ann. Surg., 65:159-69, 1917.

Loukas, M.; Hullett, J. \& Wagner, T. Clinical anatomy of the inferior phrenic artery. Clin. Anat., 18:357-65, 2005.

Mitchels, N. A. Blood supply and anatomy of the upper abdominal organs with a desciptive atlas. Philadelphia, J. B. Lippicott Company, 1995. pp.139-43.
Ozbulbul, I. N.; Yurdakul, M.; Tola, M.; Akdogan, G. \& Olcer, T. Can multidetector row CT visualize the right and left inferior phrenic artery in a population without disease of the liver? Surg. Radiol. Anat., 31:681-5, 2009.

Piao, D. X.; Ohtsuka, A. \& Murakami, T. Typology of abdominal arteries, with special reference to inferior phrenic arteries and their esophageal branches. Acta Med. Okayama, 54:189-96, 1998.

Ruzicka, F. F. Jr. \& Rossi, P. Normal coeliac and hepatic arteriogram. N.Y. State J. Med., 68:3032-44, 1968.

Saeed, M.; Murshid, K. R.; Rufai, A.A.; Elsayed, S. E. \& Sadiq, M. S. Coexistence of multiple anomalies in the celiacmesenteric arterial system. Clin. Anat., 16(1):30-6, 2003.

Saga, T.; Hirao, T.; Kitashima, S.; Watanabe, K.; Nohno, M.; Araki, Y.; Kobayashi, S. \& Yamaki, K. An anomalous case of the left gastric artery, the splenic artery and hepatomesenteric trunk independently arising from the abdominal aorta. Kurume Med. J., 52:49-52, 2005.

Standring, S. M. (ed.) Gray's Anatomy. 39 $9^{\text {th }}$ ed. Edinburgh, Elsevier/Churchill Livingstone, 2005. pp. 1118-20.

Van Damme, J. P. \& Bonte, J. The branches of the celiac trunk. Acta. Anat., 122:110-4, 1985.

Yamaki, K.; Tanaka, N., Matsushima, T.; Miyazaki, K. \& Yoshizuka, M. A rare case of absence of the celiac trunk: the left gastric, the splenic, the common hepatic and the superior mesenteric arteries arising independtly from the abdominal aorta. Ann. Anat., 177:97-100, 1995.

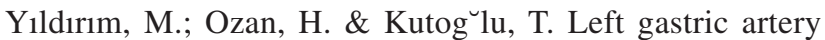
originating directly from aorta. Surg. Radiol. Anat., 20:303$5,1998$.

Yi, Q. S.; Terayama, H.; Naito M.; Hayashi, S.; Moriyama, H.; Tsuchida, A. \& Itoh, M. A. common celiacomesenteric trunk, and a brief review of the literature. Ann. Anat., 5:4828, 2007.

\section{Correspondence to:}

Nadire Unver Dogan

Adress: Selcuk University

Meram Medical Faculty

Department of Anatomy,

Konya

TURKEY

Phone number: +903322236602

Email: nunver2003@yahoo.com

Received: 01-06-2010

Accepted: 11-12-2010 